\title{
Musical Signal Processing Based on Digital Signal Processing Technology
}

\author{
Yuying Liu \\ College of Communication and Electronics, Jiangxi \\ Science \&Technology Normal University, Nanchang, \\ China \\ e-mail: 502625690@qq.com
}

\begin{abstract}
With the rapid development of computer and information, the theory and application of digital signal processing achieved great progress, which was widely applied in audio frequency field, The use of digital signal processing technology made it more flexible and convenient to record and process musical signal. This paper is going to analyze the application of digital signal processing technology in musical signal processing in two aspects: firstly, using digital signal processing time domain technology to add delay and reverberation to the recorded musical signal; secondly, using digital signal processing frequency domain technology to balance the frequency of the recorded musical signal.
\end{abstract}

Keywords-digital signal processing; musical signal; time domain; frequency domain; reverberation; frequency balance

\section{INTRODUCTION}

With the development of digital signal processing technology, which interfered increasingly vast, what's more, it is commonly used in visual and audio technology. The use of digital signal processing technology made it more flexible and convenient to record and process musical signal. There are mainly two respects of processing musical signal, for one thing, to guarantee the music recorded in soundproof recording studio can better imitate the music fabulously performed in music hall, and how to use digital signal processing technology to add delay and reverberation to the recorded music. For another, in the course of mixing the sound, recording director should know how to carry out the balance processing of the recorded signal in frequency domain and revise the music performed by sole music instrument or performer.

\section{Musical Signal Processing By Time Domain METHOD}

Usually, most musical signal recording was carried out in soundproof recording studio, the sound released by each musical instrument was collected by the near particular microphone and then recorded in one of the 48 orbits of multi track tape recorder, therefore, music came into being through sound mixing, which was unnatural and the voice is dry usually. However, the acoustic wave of the music performed in music hall was disseminated in all directions, and it was sent to the audience with many times reflection in all directions in different time. As a result, the audience can receive 3 kinds of sound signal, firstly, it was disseminated directly to the audience; secondly, the echo reflected in early

\author{
Liangliang Chen \\ College of Communication and Electronics, Jiangxi \\ Science \&Technology Normal University, Nanchang, \\ China \\ e-mail: 38295162@qq.com
}

period. The time of audience hear the echo was uncertain because it was reflected in all directions in early period. Thirdly, the reverberation reflected group that was formed in many times repeatedly reflection, the amplitude of reverberation was decreased with time according to index pattern. The absorb characteristics of different substance was related to frequency. The reverberation time and reflection strength of musical signal was different among different frequency. All the reverberation of a single sound source in recording studio can be seen in fig. 1. In order to guarantee the recorded musical signal has the same ideal music as the music performed in music hall, the recording director have to process all kinds of musical signal and add delay and reverberation to recorded signal.

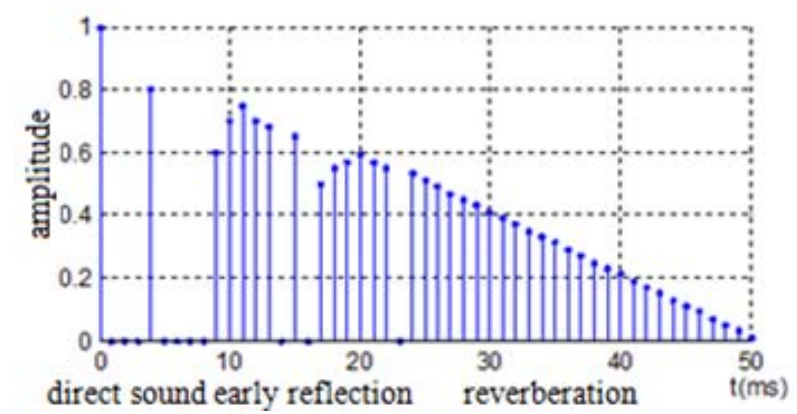

Figure 1. All the reverberation of a single sound source in recording studio.

\section{A. Single Echo Filter}

Single Echo Filter is a kind of T order FIR comb filter. The input signal can get the mixed sound of itself and its' reflected sound. The mathematic model and system function are as follows:

$$
\begin{gathered}
y(n)=x(n)+\alpha x(n-T) \\
H(z)=1+\alpha z^{-T}
\end{gathered}
$$

$\mathrm{T}$ is the delayed time relative to direct sound; $\alpha$ is amplitude attenuation. If $\alpha=0.8$ and $\mathrm{T}=4$, the network structure unit impulse response and frequency response amplitude compose of single echo filter are shown in figure 2. 

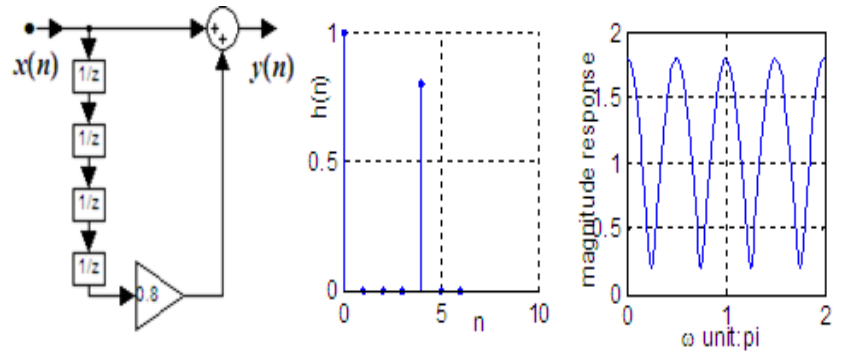

Figure 2. The network structure, unit impulse response and frequency response amplitude compose of single echo filter.

\section{B. Multiple Echo Filter}

In order to reach early reflection, the signal need to have several times emission and it can be achieved by multiple echo filter. The mathematic model and system function of a $(\mathrm{N}-1)$ order multiple echo filter is:

$$
\begin{gathered}
y(n)=x(n)+\alpha x(n-T)+\cdots \cdots+\alpha^{N-1} x[n-(N-1) T] \\
H(z)=\frac{1-\alpha^{N} z^{-N T}}{1-\alpha z^{-T}}
\end{gathered}
$$

If $\alpha=0.8$ and $\mathrm{T}=4$, this multiple echo filter is a $\mathrm{T}$ order IIR digital filter, the input signal can get the mixed sound of itself and its' (N-1) reflected sound the network structure and multiple echo filter 、 unit impulse response and frequency response amplitude compose are shown in figure 3 .
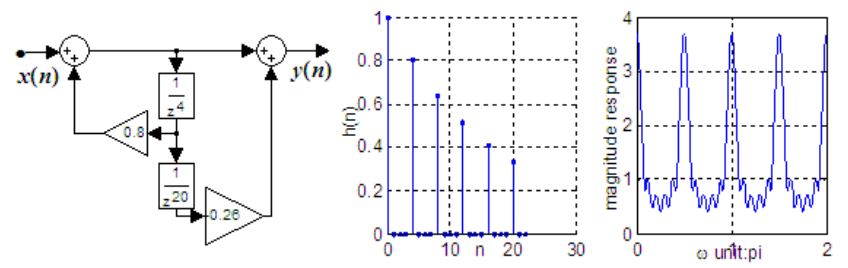

Figure 3. The network structure, unit impulse response and frequency response amplitude compose of multiple echo filter.

\section{Infinite Echo Filter}

If we want produce infinite echo, then $\mathrm{N} \rightarrow \infty$ and $\alpha \rightarrow 0$, it serves as reflection signal and delay $\mathrm{T}$, the system function of this $\mathrm{T}$ order infinite echo digital filter is:

$$
H(z)=\frac{z^{-T}}{1-\alpha z^{-T}}
$$

If $\alpha_{=0.8}$ and $\mathrm{T}=4$, the network structure、 unit impulse response and frequency response amplitude compose of infinite echo filter are shown in figure 4.
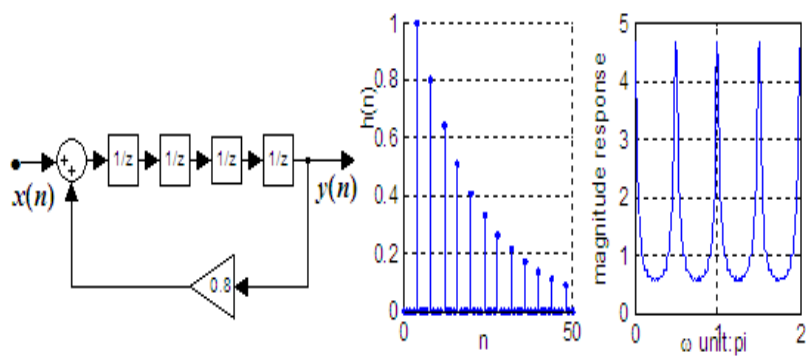

Figure 4. The network structure, unit impulse response and frequency response amplitude compose of infinite echo filter.

\section{All-pass reverberation}

The amplitude characteristic of infinite echo filter is not stable, the all-pass reverberation can save this problem. The system function of all-pass reverberation is:

$$
H(z)=\frac{\alpha+z^{-T}}{1+\alpha z^{-T}}
$$

If $\alpha=0.8$ and $\mathrm{T}=4$, the network structure 、 unit impulse response and frequency response amplitude compose of allpass reverberation are shown in figure 5.
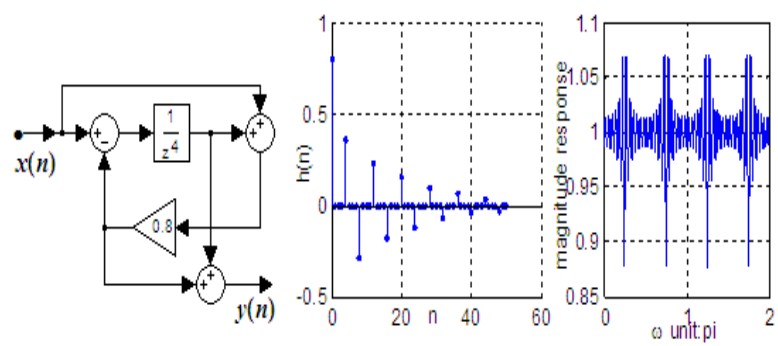

Figure 5. The network structure, unit impulse response and frequency response amplitude compose of all-pass reverberation.

\section{MUSICAL SIGNAL PROCESSING IN FREQUENCY DOMAIN METHOD}

In the course of mixing the sound, recording director should know revise the music performed by sole musical instrument or performer in order to make this weak music instrument like guitar have a plump sound, we need to increase the low frequency section from 100 to $300 \mathrm{~Hz}$. And we need to increase the high frequency section from 2 to 4 $\mathrm{kHz}$ so as to make the voice of finger touching and playing the piano string more obvious. What's more, for a high fragility of striking the musical instrument, it is needed to elevate the frequency section from 1 to $2 \mathrm{kHz}$. The digital filter technology can successfully accomplish the processing of musical signal, we can revise the high and low frequency section with the better use of inclination. We can use two order peaking filter to finish the frequency balance as well. 


\section{A. One Order Low-pass or High-pass Inclination Filter}

According to complementary law, we can design a one order low-pass or high-pass inclination filter with the use of a all-pass filter that have adjustable parameter. See it in figure 6.

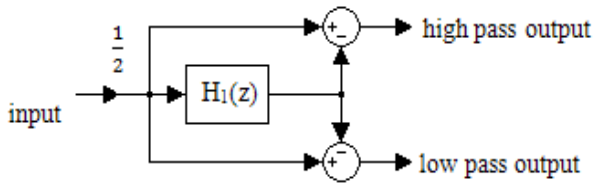

Figure 6. Complement one order low-pass or high-pass filter.

The system function of one order all-pass filter is:

$$
H_{1}(z)=\frac{\alpha-z^{-1}}{1-\alpha z^{-1}}
$$

The system function of one order low-pass or high-pass filter is:

$$
\begin{aligned}
& H_{L P}(z)=\frac{1}{2}\left[1-H_{1}(z)\right] \\
& H_{H P}(z)=\frac{1}{2}\left[1+H_{1}(z)\right]
\end{aligned}
$$

The $3 \mathrm{~dB}$ cut-off frequency $\omega \mathrm{c}$ of one order low-pass or high-pass filter is $\operatorname{arcos}(2 \alpha /(1+\alpha 2))$.

Combining the complement one order low-pass or highpass filter can form the low and high frequency filter that have adjustable parameter.

The system function of low and high frequency inclination filter is:

$$
\begin{aligned}
& G_{L P}(\mathrm{z})=k \mathrm{H}_{L P}(\mathrm{z})+\mathrm{H}_{H P}(\mathrm{z}) \\
& G_{H P}(\mathrm{z})=k \mathrm{H}_{H P}(\mathrm{z})+\mathrm{H}_{L P}(\mathrm{z})
\end{aligned}
$$

The network structure of low and high frequency inclination filter is shown in figure 7(a)、(b), frequency response amplitude compose of low and high frequency inclination filter is shown in figure 8、9.

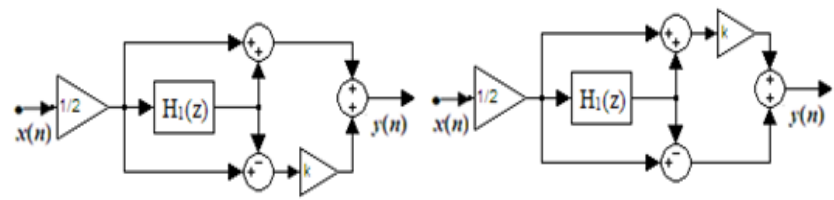

(a)

(b)

Figure 7. The network structure of low and high frequency inclination filter.
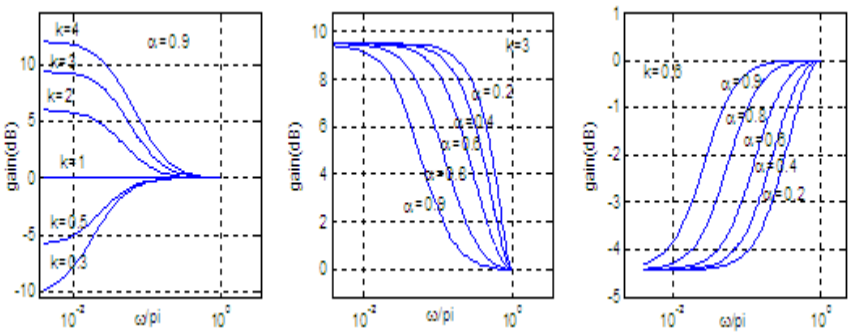

Figure 8. Frequency response amplitude compose of low frequency inclination filter.
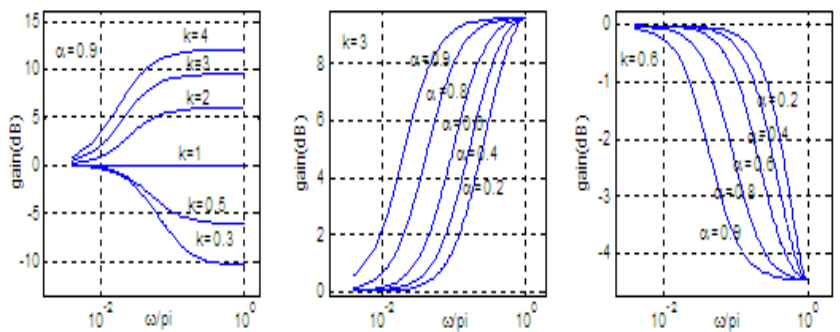

Figure 9. Frequency response amplitude compose of high frequency inclination filter.

The low and high frequency inclination filter can control the pass stripe amplitude by adjustable parameter $\mathrm{k}$. when $\mathrm{k}<1$, the pass stripe get weak; $\mathrm{k}=1$, maintain the same state; $\mathrm{k}>1$, the pass zone strengthen and we can adjust $\alpha$ to control stripe width.

\section{B. Two Order Sharpening Equalizer}

Likely according to complementary law, we can design two-order band-pass filter and band elimination filter with the use of two order all-pass filter that has two adjustable parameter. See it in figure 10

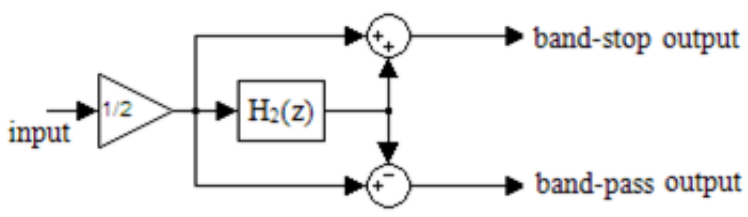

Figure 10. The network structure of two-order band-pass filter and band elimination filter. 
The system function of two order all-pass filter is:

$$
H_{2}(z)=\frac{\alpha-\beta(1+\alpha) z^{-1}+z^{-2}}{1-\beta(1+\alpha) z^{-1}+\alpha z^{-2}}
$$

The system function of two-order band-pass filter and band elimination filter is:

$$
\begin{aligned}
& H_{B P}(z)=\frac{1}{2}\left[1-H_{2}(z)\right] \\
& H_{B S}(z)=\frac{1}{2}\left[1+H_{2}(z)\right]
\end{aligned}
$$

The two order band-pass filter's central frequency and band elimination filter's trap frequency $\omega_{0}$ and $3 \mathrm{~dB}$ stripe width Bw is:

$$
\omega_{0}=\arccos (\beta)
$$

$$
B_{w}=\arccos \left(\frac{2 \alpha}{1+\alpha^{2}}\right)
$$

The output group of two-order band-pass filter and band elimination filter can form two order sharpening equalizer that have adjustable parameter:

$$
G_{2}(z)=k H_{B P}(z)+H_{B S}(z) \quad k>0
$$

The network structure and frequency response amplitude compose of two order sharpening equalizer is shown in figure 11、12.

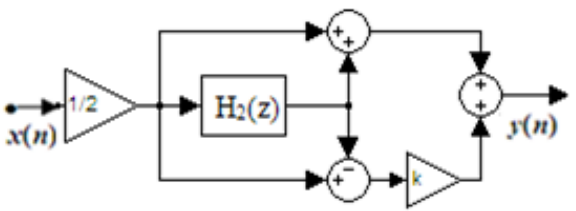

Figure 11. The network structure of two order sharpening equalizer.
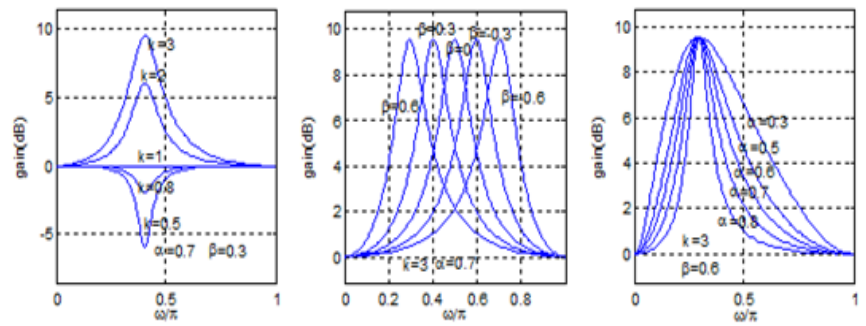

Figure 12. The frequency response amplitude compose of two order sharpening equalizer.
The parameter $\beta$ control the central frequency $\omega_{0}$ independently, the parameter $\alpha$ adjust the $3 \mathrm{~dB}$ stripe width $\mathrm{Bw}$, the higher and lower value of amplitude and frequency is adjusted according to $\mathrm{k}=\mathrm{G}_{2}\left(\mathrm{e}^{\mathrm{j} \omega 0}\right)$, so $\alpha, \beta$, $\mathrm{k}$ can adjust the amplitude compose to realize middle frequency balance.

\section{CONCLUSION}

In the course of music signal time domain processing, the echo produced by infinite echo IIR filter and all-pass filter are not closely concentrated, it is easy to occur echo trembling, in order to relatively reach the same effect of the reverberation performed in music hall. Usually, we can combine the infinite echo IIR filter and all-pass filter, and the general interconnection plan is using 4 infinite echo IIR filter in parallel and then cascade connected with two allpass filter, as a result, it can produce the same reverberation effect sound as music hall. In the course of music signal frequency domain processing, different frequency section correction should use different types of filter, the revising of high and low frequency band should use inclination filter, the middle frequency section should use sharpening equalizer, and other types of filter would be used in the process of recording and transmission. The new theory and new technology of digital signal processing are emerging and developing, and it will have a more widely application in the musical signal processing.

\section{REFERENCES}

[1] X.Q. Gao, Y.M. Ding. Digital Signal Processing-Principles Implementation and Application. Beijing: Electronic Industry Press, 2010. 274- 286.

[2] H.C. Chen, D.Z. Wu. MATLAB and Application in the Electronics Information Class Course. Beijing: Publishing House of Electronics Industry, 2006. 45- 83 .

[3] X.H. Tang, H.L. Yue. MATLAB and Application in the Electronic Information Class Course. 2nd ed.. Beijing: Publishing House of Electronics Industry, 2009. 79- 299.

[4] Sanjit, K.M. Digital Signal Proccessing-A Computer-Based Approach. 3rd ed.. Beijing: Publishing House of Electronics Industry, 2006. 478- 531 .

[5] C.Y. He. MATLAB Application and Experiment Tutorial. Beijing Publishing House of Electronics Industry, 2010. 83- 207.

[6] J.L. Zheng, Q.X. Ying, W.L. Yang. Signals and Systems.3rd ed. Beijing: Higher Educational Press, 2000. 224- 230.

[7] D.Z. Wu, L.Y. Yang, Y.R. Zhang, S.L. Wang, B.L. Guo. Signal and Linear System Analysis.4th ed... Beijing: Higher Educational Press, 2005. 243- 257.

[8] Michaels, Roberts. Sigmals and Systems. Hu Jianling,eds. Beijing China Machine Press, 2006. 312- 317.

[9] Z.Z. Guan, G.K. Xia, Q. Meng. Signals and Linear System.. 4th ed. Beijing: Higher Educational Press, 2004. 198- 205.

[10] Meret Oppenheim A.V eds. Signals and Systems. 2nd ed.. Liu Haitang. Xi'an: Xi'an Jiaotong University Press, 2000. 254-261.

[11] P.Q. Cheng. Digital Signal Processing Tutorial. 3rd ed.. Beijing: Tsinghua University Press, 2007. 196- 220.

[12] F.W. Wang, D.M. Shui, H.C. Zhao. Digital Signal Processing. 2nd ed.. Beijing: Beijing University of Posts and Telecommunications Press, 2007. 181- 189 